\title{
Employees' Perception of the Impact of Electronic Devices on the Performance of Small and Medium Size Enterprises (SME's) in Cameroon
}

\author{
Penn Emmanuel Mbuh ${ }^{1, *}$, Martha Abeja Ekure ${ }^{2}$, Vivian Neba Akosso ${ }^{1}$, Alain Vilard Ndi Isoh ${ }^{1}$ \\ ${ }^{1}$ School of Business Management and Sustainability, The ICT University, Yaounde, Cameroon \\ ${ }^{2}$ Makerere University Business School, Makerere University, Kampala, Uganda \\ Email address: \\ pennemmanuel@gmail.com (P.E.Mbuh),mabeja@mubs.ac.ug (M.A. Ekure), vivianakosso@yahoo.com (V. N. Akosso), \\ alainvilard.isoh $@$ ictuniversity.org (A. V. N. Isoh) \\ ${ }^{*}$ Corresponding author
}

\section{To cite this article:}

Penn Emmanuel Mbuh, Martha Abeja Ekure, Vivian Neba Akosso, Alain Vilard Ndi Isoh. Employees' Perception of the Impact of Electronic Devices on the Performance of Small and Medium Size Enterprises (SME's) in Cameroon. American Journal of Operations Management and Information Systems. Vol. 5, No. 1, 2020, pp. 13-19. doi: 10.11648/j.ajomis.20200501.12

Received: February 26, 2020; Accepted: March 12, 2020; Published: March 23, 2020

\begin{abstract}
The human resource is the most vital sector of every business, and with the fast evolution of technology, Information and Communication Technology (Further-ICT) is becoming more of a necessity in every sector of business rather than an option. Due to the importance of Employees, the study seeks to assess the perception of the use of electronic devices on company's performance [Small and Medium Size Enterprises (Further-SMEs)]. It is based on the positivism epistemology and the ontology of objectivism. The research used a survey method to collect data using well-structured questionnaires administered to some SMEs in Cameroon using probability sampling technique and data was analysed and interpreted using SPSS. The study works on the assumption that electronic devices have a positive impact on employee's efficiency and on the performance of SMEs in Cameroon. The study concluded that, electronic devices (when used for training and production), has a significantly positive effect on the performance of SMEs in Cameroon. Since the study was based on the perception of employees, the research recommends that a cross sectional analysis should be done on companies using electronic devices and those not using to properly ascertain its effect.
\end{abstract}

Keywords: Electronic Devices, ICT, Performance, SMEs, Cameroon

\section{Introduction}

The definition and nature of SMEs varies from country to country [1] Usually, SMEs are defined by their number of employees and their turnover. According to [1], SMEs in sub saharam countires are those that have from 1-250 employees. The world is becoming more digitized, with ICT being applied and adapted in almost every sector of government and private businesses [2]. ICT is no longer an option in private businesses and government operations but rather a necessity [3]. In the past, electronic devices like computers were very big and very expensive and were only used by large government organizations, but the invention of the fourth generation of computers in 1971 which had microprocessors, led to devices like personal computers and smart phones [4], which were cheaper both to acquire and manage thus making it possible and affordable for SMEs to own and operate an electronic system. A report released by the World Bank in 2005 highlights positive contributions of ICT in development both for government entities and for private businesses. It is now common to see policy makers focus on e-education, ehealth, e- commerce, e- finance, e- government as an overall development strategy [2].

In every organization, the organ that keeps it going is its human resource sector [5]. [5] believed that employees are very vital in every strategic decision making process in an organization or business. An organization is inoperable without its personal thus the more efficient an employee, the more successful an organization becomes. Integrating ICT in to the human resource sector does not only improve the 
efficiency of the employees but also improves the performance of that organization.

\section{Problem Statement}

Before the invention of computers, every activity was done manually (using hands, papers and pens). After the industrial revolution, work been done by human beings was now done by machines. Then came the age of ICT, where almost every task has been digitalized [2]. While large organizations are embracing this change, most SMEs are still using the manual method [6]. It is vital for organizations to abandon the handy traditional ways and embrace electronic ones [3]. ICT is becoming more of a necessity rather than an option, thus it is imperative that businesses, especially growing businesses integrate it in as many feasible sectors and departments of their operations as possible.

The survival and growth of SMEs is of great advantage to not just the proprietors and employees, but also to the economy. SMEs have a huge impact on the GDP of an economy [6, 7], contributing over $34 \%-36 \%$ on the economies GDP and employing over $80 \%$ of the population in Cameroon [8]. Thus it is imperative to focus critically into every sector of SMEs, especially those that can aid its growth and continuous survival. ICT is one of those crucial elements to SME's survival [6] because it is taking over the world. Some of the largest companies in the world have no physical location nor product, for instance the largest taxi company in the world doesn't own a single taxi (Uber), the largest store has no inventory (Alibaba) and the largest house rental platform doesn't own a single house (Airbnb) [8]. SMEs in Cameroon usually die within the first 5 years of their creation, thus it is imperative to find strategies to help them grow.

\section{Aim of the Study}

The main aim of this study is to examine the employees' perception of the impact of the application and effective use of electronic devices on the performance of SMEs.

\section{Hypothesis of the Study}

This study has one independent variable (Electronic Devices) and one dependent variable (SME's performance). To better analysis this theme a hypothesis was developed as follows;

1. H1- Electronic devices have a positive significant impact on employees performance

2. Ho- Electronic devices does not have a positive significant impact on employees performance

\section{Literature Review}

\subsection{Theoretical Review}

\subsubsection{Technology Adoption}

Technology is an external force so difficult to forecast that managers are often confused about how to design it successfully especially in Small and Medium Enterprises
(SMEs) where investment in technology is seen as very high and expensive to manage. Spending much money on procurement of new technology means a deviation from manual (simple) to sophisticated and automatic ways [9].

Technological change in most cases needs more training and intensive capital which most SMEs don't think it is worth incorporating despite the achievement of new business opportunities for organizations. SMEs engaged in manufacturing goods face a problem of loose (idle) and repetition of work (which can be remedied by ICT). Also, with service providers, ICT makes information processing faster to network clients, customers and other stakeholders worldwide through internet. That is why many active organizations through the acceptance of new technologies are able to move ahead while others are left behind in competitive markets [10]. The demand of higher technology firms require that much bigger emphasis be placed on expectations and positioning the firm for technological change that is essential in other industries [11].

The need to acquire technology creates basic tensions between the desire to use the best technology (often found outside the firm) and the desire for control. Organizations that have achieved a sophisticated understanding of the dynamics of technology are in a better position to develop competencies with which they can react appropriately to environmental and market changes. Therefore, in either reacting to or forecasting technological change, the nature of technological development must be well understood [12].

\subsubsection{Technological Change on Organizational Performance}

Technological change and its impact on the work force has become a focus of attention all over the world [5]. However, there are conflicting views about the implications of changing technology for employment. Some experts say that the pace of technological change is accelerating and that thousands of workers in plants and offices are affected as labour saving innovations is diffused more widely [8]. Others contend that recent innovations represent a sharp departure from earlier changes, and techniques for maintaining job security is essential. Technological change is beneficial for all groups in any society; it is believed that technology ultimately creates more jobs than it eliminates especially in small and medium enterprises. "Concerns about changing technology have been continual over human history and usually increasing during periods of higher than average unemployment, and abating somewhat [13]."

\subsection{Empirical Review}

\subsubsection{Use of Electronic Devices in SMEs}

An extensive body of literature exists on the usage and adoption of electronic gadgets, however most of the existing studies have concentrated on electronic gadgets and IT usage in general. Regrettably empirical studies and theory on how electronic gadgets influence performance of business is still scanty. Some research has been carried out on the relationship between business performances and the use of electronic gadgets and the factors influencing the use of electronic 
gadgets in modern businesses. Firm performance in SMEs is critically dependent on how well these electronic gadgets are used and implemented. Successful usage requires human resource training on usage and attainment of the necessary skills [14]. Usage of ICT and the related electronic gadgets is to improve deliver of and access to effective and efficient management of businesses [15], if well utilized these leads to an increase in quality of service therefore having a positive impact on the performance of the SMEs. The linkage of usage of ICT and electronic gadgets to the running of SMEs is essential on order to achieve intended outcomes of the business. Electronic gadgets have become widespread and usage is continuing to grow at a rapid rate. The total global expenditure on IT related gadgets is increasing at 5 percent per year and consequently, is doubling every 15 years [16].

Trends in SMEs suggest that with the passage of time there is a proportionate increase in production as a result of an increase in usage of ICT and electronic gadgets [17]. This may be due to many factors for example the fact that usage has expanded from the traditional activities of IT that used to be audio- visual services to a host of professional services where ICT and electronic gadgets are used such as software and information services, engineering and legal services, e commerce and trade, electronic communication and other internet based service offerings. The management teams of SMEs therefore need to understand the implication of these new revolutions which requires that they adjust and learn how to benefit from it [14].

\subsubsection{Management of ICT and Electronic Devices}

ICT and electronic gadgets have both positive and negative impacts on work environments. In the case of SMEs it is widely accepted that usage of ICT and electronic gadgets increases productivity if they are well managed and handled. Developing countries are now realizing that they can achieve significant productivity gains from their usage but they however need to be moderated by factors like Human resource training and openness to investment [16]. [16] further asserts that electronic gadgets enable businesses produce more efficiently as earlier mentioned however this may depend on the size of the network and gadgets used. The number of persons connected to the web/gadgets or if the information on the web or gadgets has expanded. The number of proficient users and staff that are trained to use gadgets and have become proficient in usage may determine the efficiency and performance of the business and the investment or capital that the business injects in to these gadgets.

Issues of quality control come into play at work places when using ICT and electronic gadgets. When things are done manually businesses may have an upper hand in quality control issues but once left for machines and gadgets this may compromise quality of services or goods thus lowering the efficiency of an enterprise [18].

\subsubsection{Training of Human Resources on Usage of Electronic Devices}

When managers want to improve the performance of their employees they need to ask a very vital question; what motivates employees to perform better? Is it pay or work environment or are there other factors that play a major role.
The development of the e -agenda is a sign that the necessary condition, attitude and policies have started to blend to effectively utilize the potential of ICT and electronic gadgets to improve on the efficiency of employees [2]. This realization has led to the development of more e-projects in developing countries and reliance on ICT for better performance in businesses especially SMEs [5]. In [5] it highlights the fact that data or information and people are unavoidably linked as never before. Either one without the other is suboptimal. Management of business entities need to avail information to employees on a timely basis for productive work to be achieved so there is need for these managements to combine ICT or access to timely information with people. Usage of ICT and the attendant electronic gadgets is a key to good performance management and improvement. The value added per employee to the business once usage of ICT gadgets is present in a business is significant in a positive way [19].

The World Bank 2015 report on ICT further affirms that in a survey of 20,000 firms in 50 low and medium income Countries, it is shown that businesses that use ICT show faster sales and employment growth as well as high labour and total factor productivity than firms that do not use ICT. This therefore points to the fact that for Human Resources to be more effective in businesses there is need to gradually introduce and train employees on ICT usage and the need to avail employees with the required gadgets to enhance their work cannot be under looked for better performance.

\subsubsection{Use of Electronic Devices in SME's and Their Effect on Efficiency and Performance of SME's}

The usage of electronic gadgets has an economic effect on SMEs' efficiency by reducing input costs and also reduces market transaction costs. Technically gadgets reduce storage space because information does not need to be stored in hard copies. Forms for example can be downloaded when required and offices made virtual [17]. This then reduces the staffing needs and the few staff can be fitted in smaller areas.

These gadgets are labour saving in businesses like supermarkets where we have self-check outs. These as a whole improves on efficiency of businesses since buyers do self-service thus no delays and long question

Economically these electronic gadgets improve economic efficiency by reducing market transactions. They also cause a reduction on prices for e-commerce commodities like electronic books, e- newspapers and a variety of these are available to clients [17].

There are however health concerns caused by these gadgets because individuals sit longer hours using them, this makes work more sedentary. Individuals sit for long hours and hardly move, thus no exercise, even outside work individuals take long hours on gadgets like phones and this may be a health problem since there is minimum exercise done.

\subsection{Conceptual Framework}

By now it is very clear the importance of ICT to a business as authors such as $[3,15,20]$ didn't shy away from emphasizing on its value. This study through the assumption of its 
hypotheses, tries to clearly show the relationship that exist between electronic devices and the performance of a SMEs.

This research models a framework using the performance of SMEs as a dependent variable and Electronic training (E-Training) and automated production as independent variables. As can be seen on the figure below, there are two independent variables; denoted as 1 for the relationship between E-training and SMEs performance and 2 for the relationship between automated production and SMEs performances

1. The study shows that if SMEs embrace electronic devices (like computers and phones) employees will use it to seek external training and the enterprise will also easily adapt to the ever changing environment of technology and this will go a long way to increase its performance in sales and market share.

2. The study also models the effects of using automated production system over the manual system. This shows that their production process will be fast, will save time and energy. This will reduce the enter prices cost and increase its market share as it will capture the young generation.

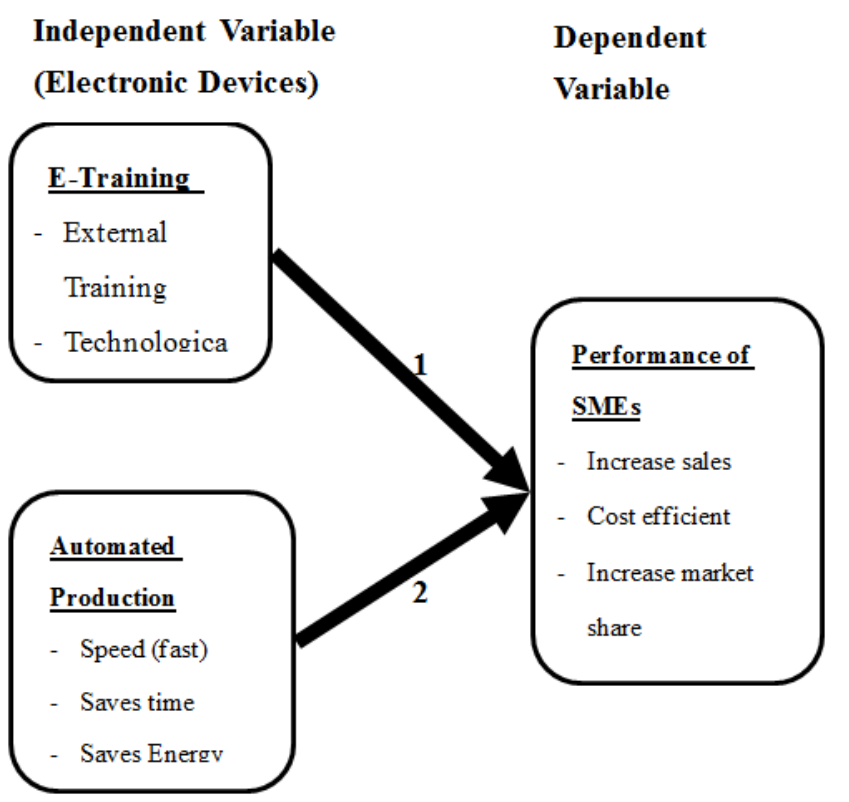

Source: Author 2020

Figure 1. Conceptual Framework.

\section{Methodology}

The research was carried out quantitative, where questionnaires were issued to 100 employees of SMEs chosen from 5 SMEs in Cameroon [21], 62 respondents filled and submitted their questions which were analyzed using SPSS statistics and AMOS. The sampling technique used was probability sampling where according to [22] the chances for any respondent to be chosen is known and equal. The research made use of both primary and secondary data collection techniques. Questionnaires were used for collecting the primary data and the secondary data was collected mainly through data mining technique. The questionnaires used were a 5 likert scales and the data collected from them examined with the threshold of reliability and validity using SPSS (EFA and CFA). The retain variables were then analyzed using regression analysis and interpretation was done.

\section{Data Analysis}

Data was analysed using SPSS statistics and SPPS Amos. Analysis of data cleaning was carried out to resolve missing values. The first step in SEM analysis is to validate the measurement models of each construct. The validity of the measurement model depends on the construct validity and model fit [23]. Therefore, the process of SEM starts with the Confirmatory Factor Analysis (CFA) to ascertain the construct validity and Goodness-of-fit of model. This research starts by carrying out an Exploratory Factor Analysis, and then a confirmatory factor analysis was done so as to retain variables that can contribute to the validity and reliability of the study. Finally regression analysis was use to test the hypothesis and make conclusions.

\subsection{Exploratory Factor Analysis}

Table 1. Combined Table of Exploratory Factor Analysis of Variables.

\begin{tabular}{llll}
\hline & \multicolumn{2}{c}{ Component } & \\
\cline { 2 - 4 } & $\mathbf{1}$ & $\mathbf{2}$ & $\mathbf{3}$ \\
\hline External Training ET1 & & .813 & \\
Technological adaptation ET5 & & .839 & \\
Fast A2 & .755 & & \\
Saves time A3 & .734 & \\
Saves energy A4 & .772 & .863 \\
24/7 services EM2 & & .862 \\
Easy access to products EM3 & & \\
Extraction Method: Principal Component Analysis. & \\
Rotation Method: Promax with Kaiser Normalization. & \\
\hline
\end{tabular}

a. Rotation converged in 5 iterations.

In the process of analysis using exploratory factor analysis, three Variables where retained that is two independent (ET and A) and 1 dependent (EM) out of the initial 6 variables implying that three other variables were cleaned-out because they did not meet the reliability and validity requirements for further analysis. However, further analysis was done in order to confirm the reliability and validity requirements of the aforementioned variables using Confirmatory analysis. The purpose was to guarantee the reliability of the retained variables (independent and dependent)

\subsection{Confirmatory Factor Analysis}

The result from the confirmatory factor analysis shows that the validity/reliability test of the independent variables and dependent variable is assured, because validity and reliability criteria have been met as seen on the figure above.

In addition further analysis using the structure equation model was carried out in order to test the hypothesis of this study. The result obtained was as follows 


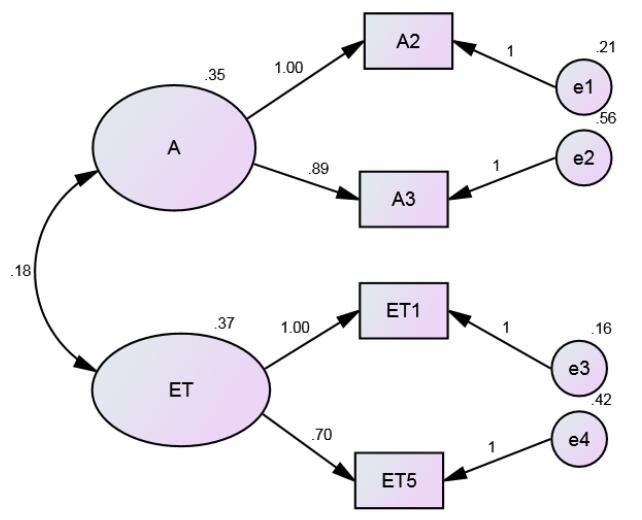

TWO FACTOR CORRELATED ANALYSIS

CMIN/DF= 1.057, $\mathrm{P}$ VALUE= 0.304, GFI= 0.990, IFI= 0.998, $\mathrm{TLI}=0.987$ $\mathrm{CFI}=\mathbf{0 . 9 9 8}, \mathrm{RMSEA}=\mathbf{0 . 0 3 3}, \mathrm{STANDARDIZED}$ RMR $=\mathbf{0 . 2 8 0}$

Figure 2. Confirmatory Factory Analysis (CFA) of Independent Variables.

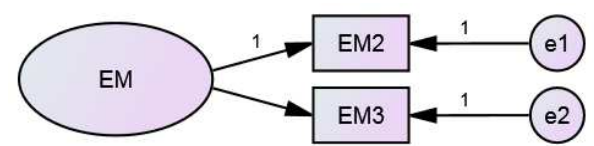

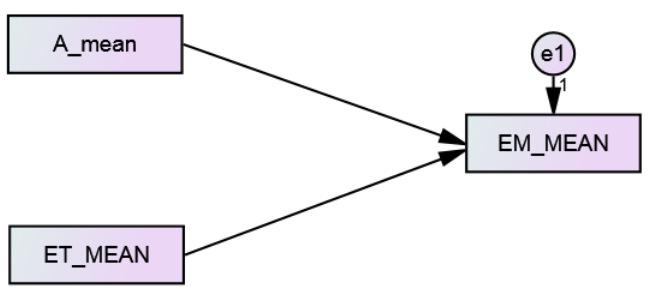

Three Factor Correlated Analysis GFI=0.926, $\mathrm{IFI}=0.727, \mathrm{CFI}=0.702 \mathrm{TLI}=0.105$ RMSEA $=0.359$

Figure 4. Structural Equation model.

From the result, the model did not fit the SEM because the variables failed to meet the reliability and validity test requirements; as a result regression analysis was used to test relationship between Electronic devices and performance of SMEs. The research applied the statistical package for social sciences (SPSS V23.0) to compute regressions for the study

Figure 3. Confirmatory Factory Analysis (CFA) of Dependent Variable.

Table 2. Regression model summery.

\begin{tabular}{lllll}
\hline Model & R & R Square & Adjusted R Square & Std. Error of the Estimate \\
\hline 1 & $.539^{\mathrm{a}}$ & .290 & .261 & .47902 \\
\hline
\end{tabular}

a. Predictors: (Constant), a_mean, ET_MEAN

b. Dependent Variable: EM_MEAN

The coefficient of determination is 0.290 , which shows that about $29 \%$ of the variation in performance can be explained by the level of use electronic devices. The percentage shows a small relationship. This study is based on the perception of employees of use of electronic devices, thus it is recommended that a cross sectional analysis be carried out to better explain the impact of electronic devices on performance

Table 3. Analysis of Variance.

\begin{tabular}{lllllll}
\hline Model & & Sum of Squares & df & Mean Square & F & Sig. \\
\hline \multirow{3}{*}{1} & Regression & 4.597 & 2 & 2.298 & 0.000225 \\
& Residual & 11.243 & 49 & .229 & \\
& Total & 15.840 & 51 & & \\
\hline
\end{tabular}

Table 4. Coefficients.

\begin{tabular}{lllllll}
\hline \multirow{2}{*}{ Model } & & \multicolumn{2}{c}{ Unstandardized Coefficients } & Standardized Coefficients & t & Sig. \\
\cline { 3 - 7 } & & B & Std. Error & Beta & 1.845 & .071 \\
\hline \multirow{2}{*}{1} & (Constant) & .537 & .291 & & 2.500 & .016 \\
& ET_MEAN & .350 & .140 & .324 & 2.517 & .015 \\
\hline
\end{tabular}

a. Dependent Variable: EM_MEAN

The $p$-values for the variables are below $0.05(0.000225)$ which is an indication that the independent variables significantly influence the dependent variable with a confidence level of $95 \%$. The regression model obtained (table 4) shows that there is a positive relationship between electronic devices and organization performance since all the coefficients are positive. This implies that everything being equal (assuming electronic devices is the only factor) a unit increase in electronic devices (for training and production) will results into a corresponding increase in performance of SMEs in Cameroon. Thus we reject the null hypothesis which states that electronic devices do not have a significant effect on performance in SMEs and accept the Alternative hypothesis which states that electronic devices have a significant positive effect on performance 
Table 5. Overall result in hypothesis.

\begin{tabular}{llll}
\hline Hypothesis & R2 & Relationship status & Result \\
\hline Ho- Electronic devices does not have a positive significant impact on employees performance & - & - & Reject \\
H1- Electronic devices have a positive significant impact on employees performance & .290 & Moderate & Accept \\
\hline
\end{tabular}

\section{Conclusion}

This study aims at examining the effects of the use of electronic devices on the performance of SMEs. It analysed many variables and using the EFA and CFA, it adopted two latent constructs (E-Training and Automated Production). The study concludes that the use of electronic devices in SMEs for training (E-Training) and production (Automated production) have a significantly positive effect on its performance with a p-value of 0.000225 which is less than the standard p-value of 0.05 . it also shows that electronic devices represent $29 \%$ of the variation in the performance of SMEs, thus we rejected the Null Hypothesis and accepted the Alternative Hypothesis which states that "Electronic devices have a positive significant impact on employees performance". The study was based on the perception of employees because employees are the backbone of an organization, contribute greatly to its success and fall. This study falls in line with a report from the world bank in 2015 which after carrying a study in 50 countries, ICT has a direct effect on the sales and growth of SMEs in developing countries like Cameroon where companies which use electronic devices had more production, sales and grew faster than companies using the manual system. It is also backed by the work of $[15,17]$ and $[16]$ who believed that electronic devices are the way forward for the development and growth of SMEs. Electronic devices are easy to manage but they come with their disadvantages such as its cost [16], both to install and to maintain and it has the potential of rendering employees unemployed. Nevertheless in the long run it is cheaper to handle and manage.

\section{Recommendation for Further Study}

A cross-sectional analysis should be carried out between firms have sophisticated electronic devices and firms without these devices to come up with a better grounded theory on the impact of these devices on performance.

Also, studies such be carried out on the effects of ICT adoption on employment, but future and present because the work done by 10 men can be done by a single device, why bacons the question; what will happen to the employyes?

\section{References}

[1] Fjose, S., Grünfeld, L. A., \& Green, C. (2010). SMEs and growth in Sub-Saharan Africa: Identifying SME roles and obstacles to SME growth. MENON Business EconomicsEssendrops gate 3, 0303 Oslo, Tlf: 971704 66, http://www.menon.no.

[2] Schware, R. (2005). E-Development: From Excitement to Effectiveness. Tunis: World Bank.
[3] Bataineh, K. A. (2017). The Impact of Electronic Management on the Employees' Performance Field Study on the Public Organizations and Governance in Jerash Governorate. Irbid National University,. Sciedu Press. ISSN 1923-3965 E-ISSN 1923-3973 http://jms.sciedupress.com Journal of Management and Strategy Vol. 8, No. 5; 2017.

[4] Kaushik. (2010). An Introduction to Microprocessor 8085. New Dhehi: Dhanpat Rai Publishing Company.

[5] Gabcanova, I. (2011). The Employees - the Most Important Asset in the Organisation. Journal of Human Resources Management \& Ergonomics.

[6] Olsan \& Eikebrokk (2009). Training, Competence and Business Performance. Evidence from E. Businesses in Europen Small and Medium Sized Enterprises 2009 International Journal of E-Business Research, 5 (1), 92-116, January-March 200

[7] Dan, A., Nicolae, I., \& Leonard, L. (2015). The Role of SMEs in Assessing the Contribution of Entrepreneurship to GDP in the Romanian Business Environment. Amfiteatru Economic, 17 (38), 195-211.

[8] Kingsley, N. (2017). Small Businesses in Cameroon: Innovation in action. Division of Research and Statistics

[9] Chandra, A. A. (2012). Marketing Potentials Of Small Andmedium Enterprises In Fiji.

[10] OLATUNJI, O. (2015). The impact informatio technology on sme's.

[11] Stella, T. D. (2017). Impact of Technological Change On Small and Medium Enterprises Performance in Lagos State (Vol. 17). Lagos, Nigeria.

[12] Council, E. a. (2018). Building digital competencies to benefit from existing and emerging technologies, with a special focus. Geneva: United nations.

[13] Qureshi, Javed \& Herani, Gobind. (2011). The Role of Small and Medium-size Enterprises (SMEs) in the Socio-economic Stability of Karachi.. Indus Journal of Management \& Social Science (IJMSS). 5. 30-44.

[14] Buseni, J. (2013). Effects of Information and Communication Technology on secretaries performance in Contemporary Organisations in Bayelsa State, Nigeria. Journal of Information and Knowledge Management.

[15] Muriuki, N. G. (2014). The Role Of Mobile Phone Use in The Success of Small and meduim size businesses. University $O f$ Nairobi.

[16] Anon H, R. G. (2017). ICT and environmental sustainability: A global perspective. Journal of Telematics and Informatics, 85-95.

[17] Tisdell, C. (2017). Information technology's impacts on productivity and welfare: a review. International Journal of Social Economics, 400-413.

[18] Shenton, A. (2009, April 8th). Is the all-electronic route a sensible option for the modern school library? 
[19] Bojnec, S., \& Gasparic, K. (2010). Factors of Efficiency of Multinational Companies in Slovenia. Journal of US - China Public Administration, 14-22.

[20] Grigore, A.-M. (2008). The Impact of Human Resources Practices upon Small Companies Performances.

[21] Meredith, J. (2002). Introduction to the special issue: case study and field research operations management. Journal of, 415-417.
[22] Saunders, e. a. (2016). Research Methods for Business Students (7th edition). Harlow: Pearson.

[23] Hair, JF, Anderson, RE, Tatham, RL \& Black, WC 1995, Multivariate data analysis with readings, 4 th edn. Prentice-Hall International, Englewood Cliffs, pp. 274. 